\title{
A TEORIA DAS INTELIGÊNCIAS MÚLTIPLAS E A FORMAÇÃO ACADÊMICA DE ESTUDANTES: UM ESTUDO DE CASO NA UNIVERSIDADE FEDERAL DO RIO GRANDE
}

\author{
TEORÍA DE LA INTELIGENCIA MÚLTIPLE Y LA FORMACIÓN ACADÉMICA DEL \\ ESTUDIANTE: UN ESTUDIO DE CASO EN LA UNIVERSIDAD FEDERAL DE RÍO \\ GRANDE
}

\author{
THEORY OF MULTIPLE INTELLIGENCE AND STUDENT ACADEMIC \\ EDUCATION: A CASE STUDY AT THE FEDERAL UNIVERSITY OF RIO GRANDE
}

\author{
Carlos Eduardo Pereira de QUADROS ${ }^{1}$ \\ Graciele Lima SAMPAIO ${ }^{2}$ \\ Diana Francisca ADAMATTI ${ }^{3}$
}

RESUMO: Este artigo apresenta uma análise de aplicação da correlação canônica sobre a teoria das inteligências múltiplas (IM) em um grupo de estudantes universitários de áreas de conhecimento diversas da Universidade Federal do Rio Grande (FURG). A ideia da pesquisa realizada é encontrar uma combinação entre a formação acadêmica dos estudantes (área de conhecimento escolhida) e as inteligências múltiplas. Algumas variáveis foram analisadas como forma de verificar se existe relação direta entre as IM e a escolha dos cursos ou áreas, como gênero, unidade acadêmica e semestre do curso. Pelos resultados obtidos, podemos concluir que existe correlação entre estas variáveis e as IM na formação de estudantes de graduação de diversas áreas e cursos na Universidade.

PALAVRAS-CHAVE: Inteligências múltiplas. Ensino superior. Análise numérica e estatística do discente.

RESUMEN: Este artículo presenta un análisis de la aplicación de la correlación canónica sobre la teoría de las inteligencias múltiples (IM) en un grupo de estudiantes universitarios de diferentes áreas del conocimiento de la Universidad Federal de Rio Grande (FURG). La idea de la investigación realizada es encontrar una combinación entre la formación académica de los estudiantes (área de conocimiento elegida) y las inteligencias múltiples. Se analizaron algunas variables como una forma de verificar si existe una relación directa entre la IM y la elección de cursos o áreas, como género, unidad académica y semestre de curso. De los resultados obtenidos se puede concluir que existe una correlación entre estas

\footnotetext{
1 Universidade Federal do Rio Grande (FURG), Campus Carreiros, Rio Grande - RS - Brasil. Centro de Ciências Computacionais - C3. TAE/Informática e Doutorando no Programa de Pós-Graduação em Modelagem Computacional - PPGMC. ORCID: https://orcid.org/0000-0002-5755-0586. E-mail: carlos.quadros@furg.br

${ }^{2}$ Universidade Católica de Pelotas (UCPEL), Campus Centro, Pelotas - RS - Brasil. Centro de Ciências Jurídicas Sociais e da Administração. Professora do Magistério Superior. ORCID: https://orcid.org/0000-00016943-6484. E-mail: graciele_sampaio@yahoo.com.br

${ }^{3}$ Universidade Federal do Rio Grande (FURG), Campus Carreiros, Rio Grande - RS - Brasil. Centro de Ciências Computacionais - C3. Professora do Magistério Superior. ORCID: https://orcid.org/0000-0003-38293075. E-Mail:dianaada@gmail.com
} 
variables y la IM en la formación de estudiantes de pregrado de diferentes áreas y cursos de la Universidad.

PALABRAS CLAVE: Inteligencias multiplex. Enseñanza superior. Análisis numérico y estadístico del alumno.

ABSTRACT: This article presents an analysis of the application of the canonical correlation on the theory of multiple intelligence (MI) in a group of university students from different areas of knowledge at the Federal University of Rio Grande (FURG). The idea of the research carried out is to find a combination between the students' academic background (chosen area of knowledge) and multiple intelligence. Some variables were analyzed as a way to verify whether there is a direct relationship between MI and the choice of courses or areas, such as gender, academic unit and course semester. From the results obtained, we can conclude that there is a correlation between these variables and MI in the education of undergraduate students from different areas and courses at the University.

KEYWORDS: Multiple intelligences. Higher education. Numerical and statistical analysis of the student.

\section{Introdução}

A teoria das Inteligências Múltiplas (teoria das IM) foi criada em 1983 por Howard Gardner através de seu livro Estruturas da mente: a teoria das inteligências múltiplas (GARDNER, 1995). A teoria faz contraponto aos tradicionais testes de Quociente de Inteligência - QI, que avaliam apenas duas habilidades: a lógico matemática e a linguística. Mesmo com o aprimoramento dos testes de QI com o passar dos anos, os testes de lápis e papel ainda continuam limitados e, de certa forma, não avaliam de maneira eficiente todas as capacidades dos indivíduos. Na teoria proposta por Gardner, foram abordadas sete inteligências: a musical, a corporal-cinestésica, a lógico-matemática, a linguística, a espacial, a interpessoal e a intrapessoal. A inteligência naturalista foi apresentada anos depois das outras sete. Portanto, temos atualmente oito inteligências no conjunto total e um vasto campo para pesquisas para serem exploradas.

O Quadro 1 (ANEXO 3 - Quadro com as características das inteligências múltiplas) apresenta um pouco das características de cada uma das oito inteligências propostas na teoria das IM de Howard Gardner. Como a teoria inicial de Estruturas da mente: a teoria das inteligências múltiplas não aborda a inteligência naturalista, foi adicionado ao quadro o trabalho de Ashton e Vernon (2006) para deixar o quadro completo com as oito inteligências.

Tomando por base o Quadro 1 com o conjunto das oito inteligências propostas por Gardner, temos a possibilidade de visualizar um pouco melhor cada uma das inteligências. 
Cabe salientar que todos temos as oito inteligências e elas trabalham de forma conjunta. Porém, algumas se destacam mais e outras menos em cada indivíduo (excluem-se dessa afirmação indivíduos que tiveram qualquer tipo de dano cerebral ou por outro motivo que tenham suas capacidades comprometidas).

De forma contextualizada, apenas no campo da teoria das IM com a área da Educação, são inúmeras as possibilidades de investigação para novas pesquisas. Dessa forma, esse trabalho se justifica como passo inicial para outras pesquisas sobre o entendimento de relação da teoria das inteligências múltiplas e o perfil discente de diversos cursos e áreas do conhecimento.

Este artigo apresenta um estudo aplicado sobre a teoria das inteligências múltiplas com um grupo de estudantes universitários de diversos cursos, de áreas de conhecimento diversas, da Universidade Federal do Rio Grande. A pesquisa tem como motivação principal a seguinte hipótese: existe ou não relação direta entre a teoria das IM e o perfil dos alunos de diversos cursos de graduação? E, ainda, caso exista relação, como ela é definida no perfil dos discentes, dos cursos e das unidades acadêmicas?

Portanto, o principal objetivo do artigo é investigar se existe ou não uma correlação entre a formação acadêmica dos estudantes (área de conhecimento escolhida) e inteligências múltiplas mais 'aplicadas'. De forma a concretizar o objetivo proposto, dois objetivos específicos foram definidos: i) coleta de dados via questionário baseado nas questões definidas por Armstrong (2017); ii) a análise dos dados obtidos.

Na sequência do texto, são apresentadas a metodologia de trabalho adotada, bem como resultados e conclusões obtidos pelo estudo realizado.

\section{Metodologia Adotada}

A metodologia adotada neste trabalho foi dividida nas seguintes etapas:

1. Montagem do questionário no google forms com base nas questões definidas por Armstrong (2017): este questionário conta com 81 questões, divididas entre as 8 inteligências. As 81 questões encontram-se no ANEXO 1 - Questões do questionário enviadas aos entrevistados; A opção pelo uso desse questionário ocorre pelo fato de sua consolidação junto à comunidade científica (GONZÁLEZ-TREVIÑO et al.., 2020) (MARTINS, 2011).

2. Disponibilização dos questionários para três unidade acadêmicas distintas da Universidade Federal do Rio Grande: Centro de Ciências Computacionais (C3), 
Instituto de Ciências Econômicas, Administrativas e Contábeis (ICEAC) e Instituto de Ciências Humanas e da Informação (ICHI). Cada uma destas unidades acadêmicas tem cursos de graduação com formação em áreas do conhecimento distintas. No C3 foram avaliados os cursos de Engenharia de Automação, Engenharia de Computação e Sistemas de Informação. No ICEAC foram avaliados os cursos de Administração, Administração - Santo Antônio da Patrulha, Ciências Contábeis, Ciências Econômicas, Comércio Exterior, Tecnologia em Gestão de Cooperativas. No ICHI foram avaliados os cursos de Arqueologia, Arquivologia, Biblioteconomia, Geografia (Bacharelado e Licenciatura), História (Bacharelado e Licenciatura), Hotelaria, Psicologia, Tecnologia em Eventos e Turismo. Estes questionários foram enviados por e-mail aos estudantes regularmente matriculados e ficaram disponíveis para respostas por 15 dias.

3. Organização dos dados obtidos: os questionários foram separados por curso e unidade acadêmica. Para cada uma das 81 questões a serem respondidas, os estudantes deveriam marcar aquelas que 'se identificam ou realizam'. Assim, o próximo passo foi somar todas as respostas positivas marcadas pelos estudantes para cada uma das 8 inteligências. Por exemplo, para a inteligência linguística, são 11 questões, sendo que um estudante pode ter marcado 5 e outro 8 .

4. Análise dos dados obtidos: após termos os dados de cada estudante, foram analisadas as unidades entre si e em seguida, em cada unidade, os cursos avaliados. Assim, podemos definir uma correlação entre a formação acadêmica dos estudantes e a área de conhecimento escolhida em diferentes unidades acadêmicas.

5. Para a análise dos dados foi utilizada a técnica de correlação canônica, por meio do software Statgraphics Centurion. A correlação canônica, conforme Mingoti (2005), busca verificar as relações lineares existentes entre dois conjuntos de variáveis. Esta técnica permite comparar ao mesmo tempo várias variáveis métricas dependentes e independentes, sendo considerada a extensão lógica da análise de regressão múltipla, visto que esta utiliza apenas uma variável dependente (HAIR JR. et al., 2009). De acordo com Fávero et al. (2009), a correlação canônica tem o objetivo de quantificar a força da relação entre as variáveis dependentes e independentes. A correlação canônica, conforme Mingoti (2005), sintetiza os conjuntos de variáveis resposta em combinações lineares e determina que os coeficientes das combinações são escolhidos a partir da maximização da correlação entre os conjuntos de variáveis-resposta. Assim, as combinações lineares são as variáveis canônicas e a correlação estabelecida entre 
elas é a correlação canônica. A correlação canônica busca medir o grau de associação entre os dois conjuntos de variáveis estudadas, desta forma, foi possível verificar a relação existente entre as inteligências múltiplas de Gardner e as características dos estudantes de graduação. Para isto, o modelo representa as matrizes X496x8e X496x5 (O software Statgraphics Centurion descartou 3 respostas automaticamente), em que X representa os 496 estudantes de graduação da Universidade conforme o Quadro 3 e $\mathrm{Y}$ as características dos estudantes, gênero, curso, semestre, unidade acadêmica e fase (iniciante ou concluinte). Deste modo observa-se na equação a relação a ser estabelecida:

$$
a 1 X 1+a 2 X 2+a 3 X 3+\cdots+a m X m=b 1 Y 1+b 2 Y 2+b 3 Y 3+\cdots+b n Y n
$$

Os questionários foram enviados a 3.313 discentes matriculados nos cursos anteriormente citados. Deste total, 499 estudantes responderam, sendo 15,06\% do total, o que é um número expressivo, visto que pesquisas sem obrigatoriedade de respostas têm, normalmente, menos de $10 \%$ de retorno (VIEIRA; CASTRO SCHUCH JÚNIOR, 2010). A divisão é apresentada no ANEXO 2 - Quadro com a divisão entre os cursos - com o total de enviados e total de respostas obtidas dos discentes das diferentes unidades acadêmicas.

O perfil dos discentes consultados, em relação ao tempo do curso e o período em que estavam, foi classificado em dois tipos: ingressantes e concluintes. Dessa forma, os discentes que estavam no início da formação, ou seja, do ingresso até alcançar 50\% do tempo de conclusão do curso, foram classificados como ingressantes. E, de maneira semelhante, os discentes que estavam mais adiantados, ou seja, da conclusão de $50 \%$ do tempo do curso até a formação completa, foram classificados como concluintes, conforme Figura 1.

Figura 1- Perfil dos discentes consultados na pesquisa em relação ao tempo de curso

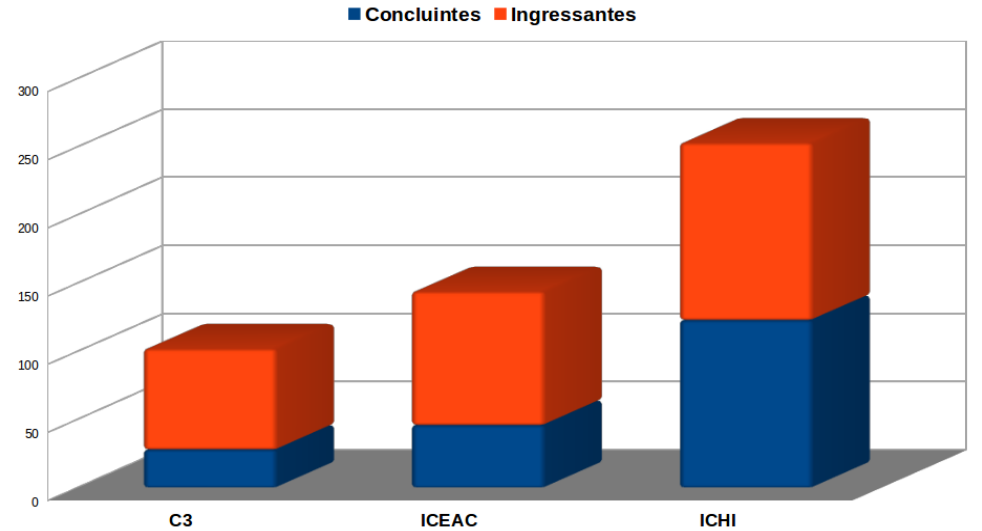

Fonte: Os autores 
O perfil dos discentes consultados, conforme suas respostas em relação ao gênero, pode ser visto na Figura 2.

Figura 2 - Perfil dos discentes consultados na pesquisa em relação ao gênero

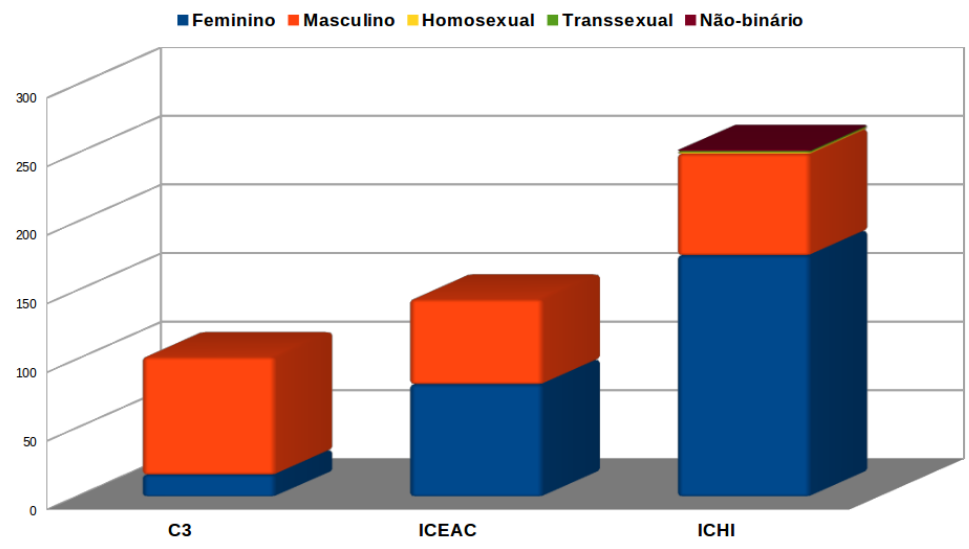

Fonte: Os autores

Figura 3 - Inteligências geral

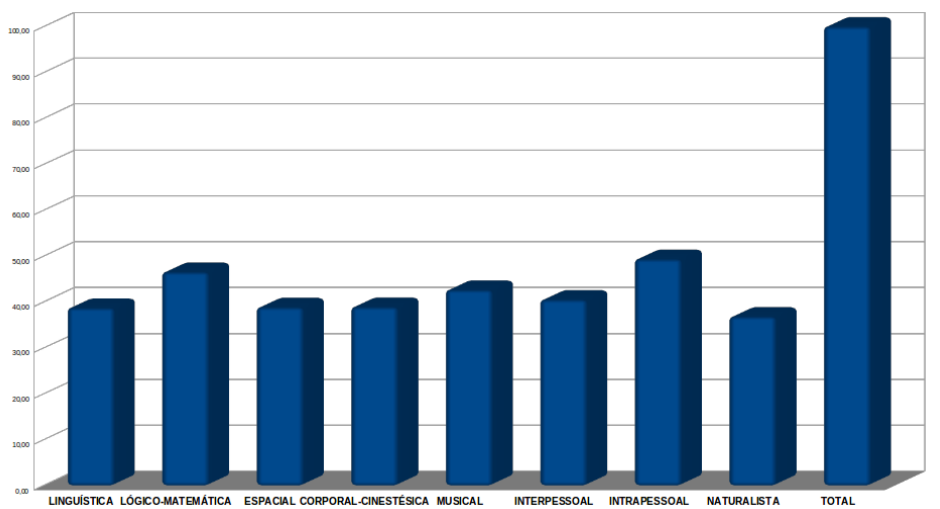

Fonte: Os autores

No geral, as respostas para as 81 questões foram retornadas por 499 estudantes. Desse total, cada inteligência tinha 10 respostas que os entrevistados poderiam marcar, exceto a inteligência linguística que tinha 11 questões. A Figura 3 representa o comparativo entre a proporcionalidade de respostas de cada inteligência e o total (representado pela última barra) de possibilidades que poderiam ser respondidas. Podemos observar através do gráfico que, em um contexto geral, nenhuma das inteligências alcançou 50\% das respostas possíveis. 
Figura 4 - Níveis de inteligências - C3

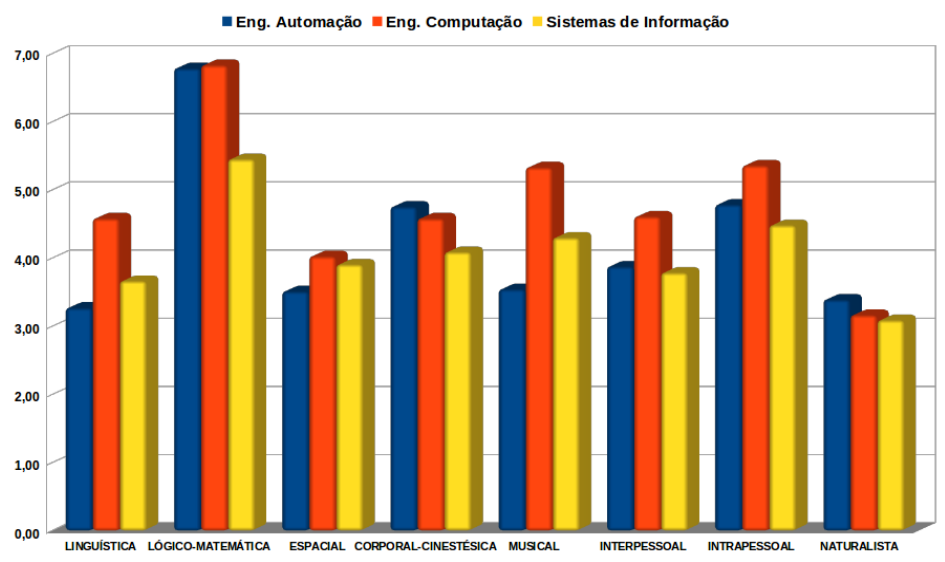

Fonte: Os autores

Figura 5 - Níveis de inteligências - ICEAC

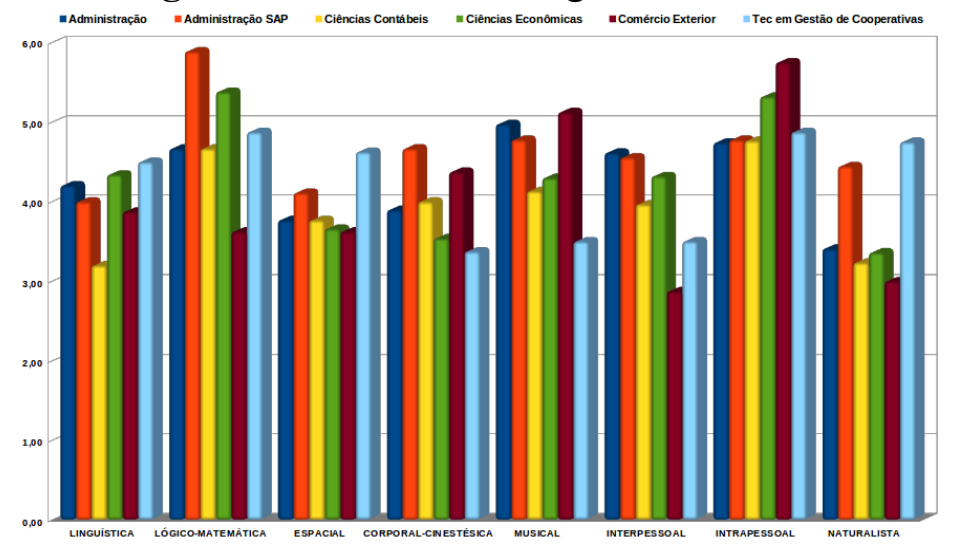

Fonte: Os autores

Figura 6 - Níveis de inteligências - ICHI 1

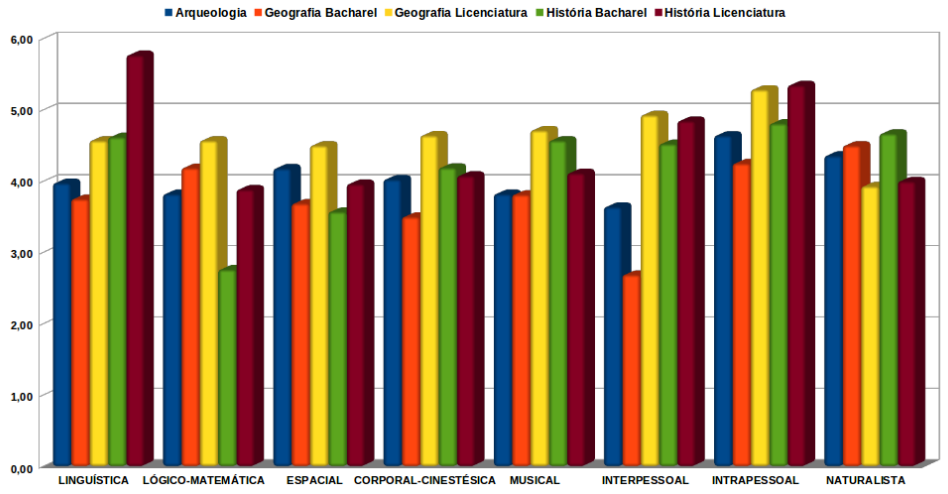

Fonte: Os autores 
Figura 7 - Níveis de inteligências - ICHI 2

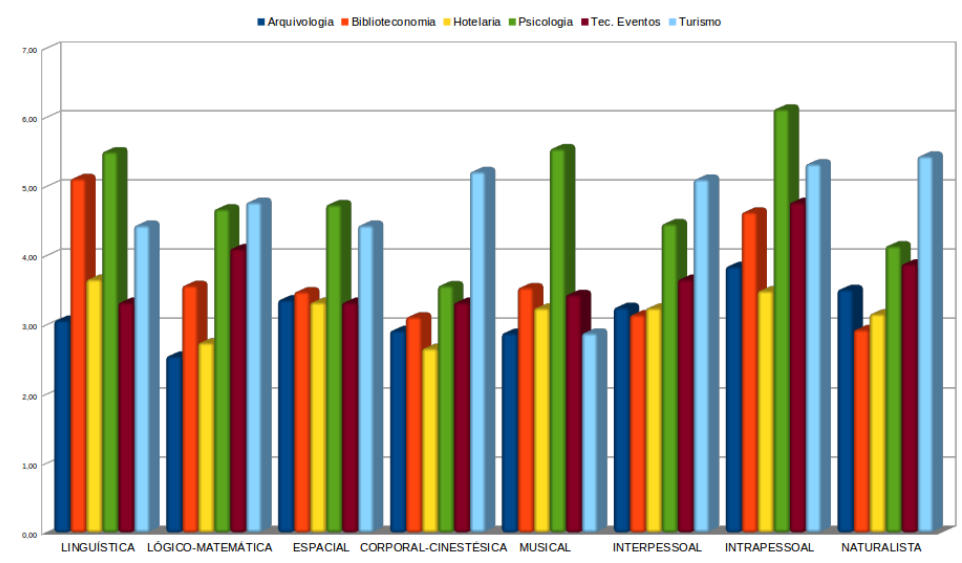

Fonte: Os autores

Nas Figuras 4, 5, 6 e 7 são apresentadas as inteligências por unidade acadêmica. Podendo cada uma das inteligências ter no máximo 10 respostas positivas (exceto a linguística que permite 11 respostas), pode-se verificar os valores para cada unidade acadêmica e cada curso, respectivamente. Como a unidade acadêmica do ICHI possui muitos cursos, o gráfico foi dividido em duas partes.

\section{Resultados}

\section{Análise da teoria das Inteligências Múltiplas nas Unidades}

A Figura 8 apresenta a comparação entre as respostas das três unidades envolvidas no estudo. Para exemplificar, a quantidade total de respostas para a inteligência linguística entre todas as unidades foi de 2.125. Entre as unidades acadêmicas, essas respostas ficaram com os seguintes valores: 394 C3, 580 ICEAC e 1.151 ICHI. De maneira proporcional, o gráfico apresenta a quantidade de respostas total da inteligência dividida pela quantidade de resposta da unidade acadêmica. Ou seja, na primeira parte da Figura 8, para a inteligência linguística, temos os seguintes valores: 3,86 C3, 4,03 ICEAC e 4,55 ICHI. 
Figura 8 - IM nas unidades acadêmicas

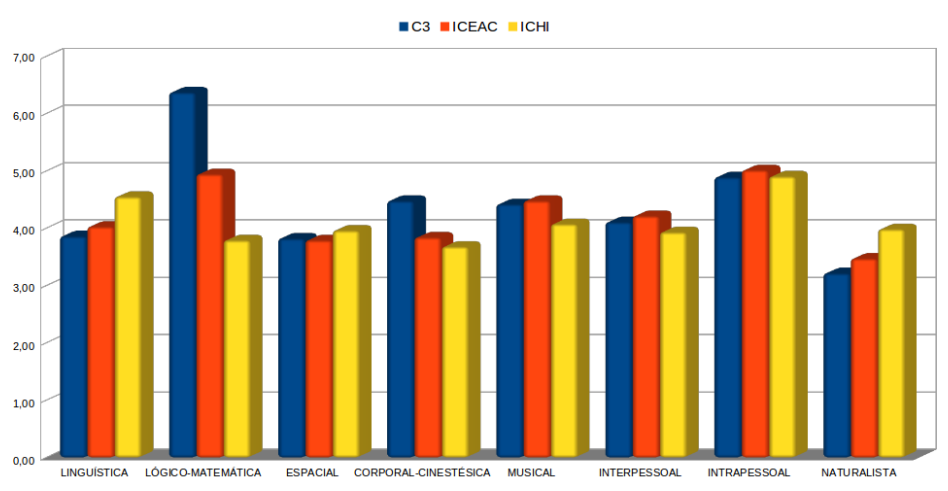

Fonte: Os autores

Quadro 1 - Valores Proporcionais das IM nas unidades acadêmicas

\begin{tabular}{|l|r|r|r|}
\hline Inteligência & $\mathbf{C 3}$ & ICEAC & ICHI \\
\hline Linguística & 3,86 & 4,03 & 4,55 \\
\hline Lógico-matemática & $\mathbf{6 , 3 7}$ & 4,94 & 3,79 \\
\hline Espacial & 3,82 & 3,79 & 3,96 \\
\hline Corporal-cinestésica & 4,48 & 3,84 & $\mathbf{3 , 6 8}$ \\
\hline Musical & 4,42 & 4,48 & 4,08 \\
\hline Interpessoal & 4,11 & 4,22 & 3,93 \\
\hline Intrapessoal & 4,89 & $\mathbf{5 , 0 1}$ & $\mathbf{4 , 9 1}$ \\
\hline Naturalista & $\mathbf{3 , 2 2}$ & $\mathbf{3 , 4 7}$ & 3,98 \\
\hline
\end{tabular}

Fonte: Dados da pesquisa

No Quadro 1 são apresentados todos os valores proporcionais para as IM nas unidades acadêmicas. Em negrito, alguns valores foram marcados, salientando algumas das inteligências em cada unidade. Primeiramente, podemos salientar o valor da inteligência Lógico-matemática no $\mathrm{C} 3$, sendo superior às duas outras unidades $(6,37)$. Isto justifica-se por ser uma unidade com cursos na área de tecnologia e engenharia. Na mesma unidade, o menor valor entre todas as inteligências é também o menor valor entre as três unidades para a inteligência naturalista $(3,22)$. Para a inteligência intrapessoal, a unidade ICEAC obteve os maiores valores $(5,01)$, mas para essa inteligência, os valores das outras unidades foram próximos $(4,89$ e 4,91), mostrando que os estudantes acreditam ter autoconhecimento. Contudo, para a inteligência interpessoal, os valores são mais baixos, respectivamente 4,11, 4,22 e 3,93. Nos estudos realizados por Pereira e Silva (2017), apenas com estudantes de psicologia, o resultado foi exatamente oposto, mostrando que os discentes tinham altos valores para a inteligência interpessoal e baixo para a intrapessoal. 
Um ponto importante a ressaltar é que os menores valores foram encontrados para a inteligência naturalista, mostrando que a educação ainda não foca para este tipo de inteligência desde o ensino básico. Sabino e Roque (2006) afirmam que adotar as inteligências múltiplas com o uso de metodologias diferenciadas, considerando características individuais de cada discente, pode contribuir no processo de ensino e aprendizagem.

\section{Análise Estatística}

Para verificar, por meio da correlação canônica, se há relação entre as inteligências múltiplas e as características dos estudantes foram utilizadas no modelo as variáveis evidenciadas no Quadro 2.

Quadro 2 - Variáveis da correlação canônica

\begin{tabular}{|c|c|}
\hline Variáveis do conjunto 1 & Variáveis do conjunto 2 \\
\hline Inteligência linguística & \multirow{8}{*}{$\begin{array}{c}\text { Gênero } \\
\text { Curso } \\
\text { Unidades Acadêmicas } \\
\text { Semestre } \\
\text { Fase (Iniciante/Concluinte) }\end{array}$} \\
\hline Inteligência lógico-matemática & \\
\hline Inteligência espacial & \\
\hline Inteligência musical & \\
\hline Inteligência corporal-cinestésica & \\
\hline Inteligência interpessoal & \\
\hline Inteligência intrapessoal & \\
\hline Inteligência naturalista & \\
\hline
\end{tabular}

Fonte: Dados da pesquisa

A correlação canônica demonstra as combinações lineares de dois conjuntos de variáveis que têm a correlação mais alta entre elas. Neste caso, 5 conjuntos de combinações lineares foram formados. No Quadro 4 é possível verificar a correlação estimada entre cada conjunto de variáveis canônicas. 
Quadro 3 - Correlações canônicas entre as inteligências múltiplas e as características dos estudantes

\begin{tabular}{|c|c|c|c|c|}
\hline & & Canonical & Wilks & \\
\hline Função Canônica & Eigenvalue & Correlation & Lambda & P-Value \\
\hline 1 & 0,242189 & $\mathbf{0 , 4 9 2 1 2 7}$ & 0,689796 & $\mathbf{0 , 0 0 0 0}$ \\
\hline 2 & 0,0674388 & $\mathbf{0 , 2 5 9 6 9}$ & 0,910247 & $\mathbf{0 , 0 1 7 9}$ \\
\hline 3 & 0,0137929 & 0,117443 & 0,976072 & 0,8565 \\
\hline 4 & 0,0060777 & 0,0779596 & 0,989724 & 0,8884 \\
\hline 5 & 0,00422435 & 0,064995 & 0,995776 & 0,7236 \\
\hline
\end{tabular}

Fonte: Dados da pesquisa

No Quadro 3 apresentam-se as combinações lineares dos dois conjuntos de variáveis que têm a mais alta correlação entre eles, neste caso, cinco conjuntos lineares foram formados. O primeiro conjunto, ou função canônica 1, é o que possui maior poder de explicação, 49,21\%, segundo Hair et al. (2009). Esta correlação é estatisticamente significativa ao nível de $95 \%$, pois o $p$-value foi inferior a $5 \%$.

No Quadro 5 apresentam-se os valores resultantes dos dois conjuntos de inputs do modelo, que compreende as 499 observações.

Quadro 4 - Coeficientes do modelo de correlação canônica

\begin{tabular}{|c|c|c|c|c|c|}
\hline \multicolumn{5}{|c|}{ Coeficientes de variáveis canônicas do primeiro conjunto } \\
\hline Variável & Função 1 & Função 2 & Função 3 & Função 4 & Função 5 \\
\hline IL & $-0,0933891$ & $-0,506662$ & $-0,867589$ & 0,140496 & $-0,499162$ \\
\hline ILM & $\mathbf{0 , 9 3 5 3 9 5}$ & $\mathbf{0 , 3 3 9 1 9 1}$ & 0,238513 & $-0,0318198$ & $-0,35228$ \\
\hline IE & $-0,202032$ & $\mathbf{0 , 3 6 2 5 5 1}$ & 0,0857004 & 0,249524 & $-0,703386$ \\
\hline ICC & $\mathbf{0 , 2 0 0 5 7 8}$ & $\mathbf{0 , 2 1 8 3 5 4}$ & $-0,799138$ & $-0,586052$ & 0,547129 \\
\hline IM & $\mathbf{0 , 2 6 3 0 6 6}$ & $-0,176053$ & 0,0315061 & 0,81708 & 0,693343 \\
\hline IITER & $-0,105814$ & $-0,407857$ & 0,599601 & $-0,252426$ & $-0,176161$ \\
\hline IITRA & $\mathbf{0 , 0 5 4 0 9 2 5}$ & $-0,65979$ & 0,400026 & $-0,345786$ & 0,218749 \\
\hline IN & $-0,308176$ & 0,000886401 & 0,218481 & $-0,230456$ & 0,131625 \\
\hline \multicolumn{7}{|c|}{ Coeficientes de variáveis canônicas do segundo conjunto } \\
\hline Variável & Função 1 & Função 2 & Função 3 & Função 4 & Função 5 \\
\hline
\end{tabular}




\begin{tabular}{|c|c|c|c|c|c|}
\hline G & $\mathbf{0 , 9 1 1 0 5 9}$ & $\mathbf{0 , 1 7 5}$ & 0,0940348 & 0,362305 & 0,265974 \\
\hline C & $\mathbf{0 , 5 4 1 7 7 9}$ & $-1,38017$ & 0,974226 & $-0,635523$ & $-1,39728$ \\
\hline U & $-0,590457$ & $\mathbf{0 , 8 4 0 0 4 5}$ & $-0,444838$ & 1,32747 & 1,62225 \\
\hline S & $-0,065338$ & $\mathbf{0 , 5 7 1 5 0 4}$ & $-0,344168$ & 1,08742 & $-1,21987$ \\
\hline F & $\mathbf{0 , 1 5 0 8 1 3}$ & $-1,12976$ & $-0,45082$ & $-0,741469$ & 1,04007 \\
\hline
\end{tabular}

Fonte: Dados da pesquisa

No Quadro 4 evidencia-se a correlação estimada entre cada conjunto de variáveis canônicas. Destaca-se que o primeiro e o segundo conjunto de variáveis canônicas têm significância estatística ao nível de confiança de 95\%. Desta forma, os coeficientes canônicos que correspondentes ao primeiro par canônico apresentam uma tendência de que, no primeiro conjunto, a variável inteligência lógico-matemática, 0,935395 teve a maior influência na associação do modelo e a variável inteligência naturalista, -0,308176 a menor influência. No segundo conjunto, a variável gênero, 0,911059 possui a maior influência na associação do modelo e em segundo lugar, a variável curso 0,541779.

Quando se observa o segundo par canônico no primeiro conjunto, a variável inteligência espacial, 0,362551 teve a maior influência na associação do modelo e a variável inteligência intrapessoal, -0,65979 a menor influência. No segundo conjunto, a variável unidade acadêmica, 0,840045 possui a maior influência na associação do modelo e em segundo lugar, a variável semestre 0,571504.

Ao se relacionar as inteligências múltiplas de Gardner e as características dos estudantes de graduação FURG na função 1, que apresentou maior poder de explicação, observa-se que há uma relação diretamente proporcional entre as variáveis: inteligência lógico-matemática (ILM), inteligência corporal cinestésica (ICC), inteligência musical (IM), inteligência intrapessoal (IITRA) e as características dos estudantes por gênero (G), curso (C) e fase $(F)$ ingressante/concluinte.

Da mesma forma, verifica-se uma relação diretamente proporcional entre as variáveis inteligência linguística (IL), inteligência espacial (IE), inteligência interpessoal (IITER), inteligência naturalista (IN) e as características unidade acadêmica (U) e semestre (S) que pertencem os estudantes.

Quando se observa a função 2, que apresentou menor poder de explicação, verifica-se que há uma relação diretamente proporcional entre as variáveis: inteligência lógicomatemática (ILM), inteligência espacial (IE), inteligência corporal cinestésica (ICC), 
inteligência naturalista (IN) e as características dos estudantes por gênero (G), unidade acadêmica $(U)$ e semestre $(S)$. Também se verifica uma relação diretamente proporcional entre as variáveis inteligência linguística (IL), inteligência musical (IM), inteligência interpessoal (IITER), inteligência intrapessoal (IITRA) e as características curso (C) e fase (F) ingressante/concluinte.

A partir destes resultados evidencia-se que há relação entre as inteligências múltiplas e as características dos estudantes de graduação, apresentando uma força da associação considerada moderada.

\section{Considerações finais}

A teoria das IM defende que a inteligência não pode ser algo singular, ou que a inteligência dos seres humanos possa ser mensurada por apenas duas áreas como a linguística e a lógico-matemática. A teoria das IM possui um conjunto de oito inteligências, que são: linguística (palavras e símbolos), Lógico-matemática (cálculos e problemas), musical (produção e compreensão de sons), corporal-cinestésica (controle e expressão corporal), espacial (percepção do espaço, dimensão e orientação), naturalista (reconhecimento e classificação do que está relacionado com a natureza), interpessoal (empatia e entendimento sobre os sentimentos de outras pessoas), intrapessoal (entendimento sobre si mesmo).

De acordo com Travassos (2001), a melhor maneira de compreender cada inteligência é concebendo-as como interrelacionadas, com possibilidade de existência de diferentes perfis intelectuais em diferentes grupos. Para o entendimento mais aprofundado na teoria das IM existem inúmeros estudos e diversas abordagens, tanto para o conjunto das oito IM, quanto para o estudo de cada uma das inteligências de modo específico. Desta maneira, neste trabalho, buscamos encontrar aspectos que correlacionassem as inteligências entre estudantes de diferentes cursos de graduação da FURG, em áreas de conhecimento diferentes. Assim, tentando definir se havia relação entre as inteligências múltiplas e sua formação. Aqui também se tinha interesse de saber quanto a formação em si pode ampliar as inteligências múltiplas, tratando-se de discentes iniciantes e concluintes de curso.

Para tanto, primeiramente apresentamos a metodologia adotada e um perfil dos estudantes que participaram do questionário. Em seguida, são apresentados os resultados numéricos, devendo ressaltar os dados do Quadro 2, e a ênfase de cada unidade e suas áreas de conhecimento mais fortemente estudadas. Na análise estatística foi possível definir e correlacionar as oito inteligências múltiplas com as variáveis gênero, curso, unidades 
acadêmicas, semestre e fase (iniciante/concluinte), que são apresentadas nos Quadros 4 e 5, mostrando como estas variáveis possuem um 'peso' sobre cada uma das inteligências. Vale destacar os valores de gênero na função 1 e de unidade na função 2. Contudo, para podermos afirmar com maior precisão sobre estes aspectos, ainda será preciso realizar mais estudos, mas percebe-se que existem diferenças entre as áreas de conhecimento e os estudantes de graduação que as escolhem para sua formação.

Como continuidade desta pesquisa, vislumbramos realizar mais testes estatísticos sobre os dados, bem como realizar uma nova rodada de questionários com o grupo de estudantes anteriormente participantes, de forma a analisar mudanças em sua formação no decorrer do tempo e fora do contexto da pandemia do COVID-19, fato que pode ter reflexos de interferência nas respostas dos discentes.

\section{REFERÊNCIAS}

ARMSTRONG, T. Multiple intelligences in the classroom. 4. ed. [S. 1.]: ASCD, 2017. $243 p$.

FÁVERO, L. P. et al. Análise de dados: modelagem multivariada para tomada de decisões. Rio de Janeiro: Elsevier, 2009.

GARDNER, H. Frames of mind: the theory of multiple intelligences. New York: Basic Books, 1983.

GARDNER, H. Inteligências múltiplas: a teoria na prática. Porto Alegre: Artmed, 1995.

GONZÁLEZ-TREVIÑO, I. M. et al. Assessment of multiple intelligences in elementary school students in Mexico: An exploratory study, Heliyon, Volume 6, Issue 4, 2020.

HAIR JÚNIOR, J. F. et al. Análise multivariada de dados. 6. ed. Porto Alegre: Bookman, 2009.

MARTINS, M. A. P. Contributions of the theory of multiple intelligences to the assessment of students' production in translator training courses. Ensaio: Avaliação e Políticas Públicas em Educação, Volume: 19, Issue: 71, 2011.

MINGOTI, S. A. Análise de dados através de métodos de estatística multivariada: uma abordagem aplicada. Belo Horizonte: UFMG, 2005.

PEREIRA, D. F.; SILVA, J. C. T. Um estudo sobre as inteligências múltiplas em estudantes de Psicologia. Revista UNIABEU, [S. 1.], v. 10, n. 24, p. 126-142, 2017.

TRAVASSOS, L. C. P. Inteligências múltiplas. Revista de Biologia e Ciências da Terra, [S. 1.], v. 1, n. 2, doc. sem paginação, 2001. 
SABINO, M. A.; ROQUE, A., S. S. A teoria das inteligências múltiplas e sua contribuição para o ensino de língua italiana no contexto de uma escola pública. Revista Eletrônica dos Núcleos de Ensino da UNESP, São Paulo, p. 410-429, 2006.

VIEIRA, H. C.; CASTRO, A. E. de; SCHUCH JÚNIOR, V. F. O uso de questionários via email em pesquisas acadêmicas sob a ótica dos respondentes. In: SEMINÁRIOS EM ADMINISTRAÇÃO, 13., set. 2010, São Paulo. Anais [...]. [São Paulo]: USP, 2010.

VISSER, B. A.; ASHTON, M. C.; VERNON, P. A. Beyond g: Putting multiple intelligences theory to the test. Intelligence, [S. 1.], v. 34, p. 487-502, 2006.

\section{Como referenciar este artigo}

QUADROS, C. E. P.; SAMPAIO, G. L.; ADAMATTI, D. F. A teoria das inteligências múltiplas e a formação acadêmica de estudantes: um estudo de caso na Universidade Federal do Rio Grande. Doxa: Rev. Bras. Psico. E Educ., Araraquara, v. 22, n. 00, p. e021007, 2021. e-ISSN: 2594-8385. DOI: https://doi.org/10.30715/doxa.v22i00.15031

Submetido em: 15/04/2021

Revisões requeridas em: 04/05/2021

Aprovado em: 06/06/2021

Publicado em: 25/06/2021 


\section{ANEXO 1}

Questões do questionário enviadas aos entrevistados

\section{Inteligência Linguística}

01 - Livros são muito importantes para mim.

02 - Ouço as palavras em minha cabeça antes de lê-las, falá-las ou escrevê-las.

03 - Aproveito (aprendo) mais ouvindo rádio ou gravações de leituras do que quando assisto à televisão ou filmes.

04 - Gosto de Jogos de palavras cruzadas, anagramas ou senhas.

05 - Gosto de me entreter e entreter os outros com trava-línguas, trocadilhos ou rimas sem sentido.

06 - As pessoas às vezes me pedem para parar e explicar o significado das palavras que uso quando escrevo ou falo.

07 - Português, estudos sociais e história eram disciplinas mais fáceis para mim na escola do que matemática e ciências.

08 - Aprender uma outra língua (por exemplo, francês, inglês, espanhol e alemão) foi relativamente fácil para mim.

09 - Quando dirijo em uma autoestrada, presto mais atenção nas palavras escritas em placas ou anúncio do que na paisagem.

10 - Meus diálogos incluem frequentemente referências a coisas que li ou ouvi.

11 - Recentemente, escrevi algo que me deixou especialmente orgulhoso ou foi reconhecido por outras pessoas.

\section{Inteligência Lógico-Matemática}

12 - Tenho facilidade para fazer cálculos de cabeça.

13 - Matemática e/ou ciências estavam entre as minhas matérias favoritas na escola.

14 - Gosto de jogos ou enigmas que exijam pensamento lógico.

15 - Gosto de fazer pequenos experimentos "e se" (por exemplo: "E se eu dobrasse a quantidade de água que coloco na minha roseira semanalmente?").

16 - Minha mente busca padrões, regularidades ou sequências lógicas nas coisas.

17 - Tenho interesse pelos progressos da ciência.

18 - Acredito que quase tudo tem uma explicação racional.

19 - Às vezes, penso em conceitos claros, abstratos, não verbais e sem imagens.

20 - Gosto de detectar falhas lógicas nas coisas que as pessoas dizem e fazem em casa e no trabalho.

21 - Sinto-me mais à vontade quando algo foi medido, categorizado, analisado ou quantificado de alguma maneira.

\section{Inteligência Espacial}

22 - Quando fecho os olhos, com frequência visualizo imagens claras.

23 - Sou sensível a cores.

24 - Frequentemente uso uma máquina fotográfica ou uma filmadora para registrar o que vejo ao meu redor.

25 - Gosto de montar quebra-cabeças, labirintos e outros jogos visuais.

26 - Tenho sonhos claros à noite.

27 - Geralmente consigo achar meu caminho em lugares desconhecidos.

28 - Gosto de desenhar ou rabiscar.

29 - A geometria era mais fácil para mim do que a álgebra, quando eu estava na escola. 
30 - Consigo imaginar facilmente como uma coisa pareceria se a víssemos de cima, panoramicamente.

31 - Prefiro ler materiais com muitas ilustrações.

\section{Inteligência Corporal-Cinestésica}

32 - Pratico pelo menos um esporte ou atividade física regularmente.

33 - Tenho dificuldade em permanecer quieto por longos períodos de tempo.

34 - Gosto de trabalhar com as mãos em atividades concretas como costurar, fazer tricô, entalhes, trabalhos de carpintaria ou modelagem.

35 - Minhas melhores ideias me ocorrem quando saio para dar uma longa caminhada, para correr ou quando estou envolvido em algum outro tipo de atividade física.

36 - Em geral, gosto de passar meu tempo de lazer ao ar livre.

37 - Frequentemente gesticulo ou uso outras formas de linguagem corporal quando converso com as pessoas.

38 - Preciso tocar nas coisas para aprender mais sobre elas.

39 - Gosto de divertimentos desafiadores ou experiências físicas emocionantes, eletrizantes.

40 - Descreveria a mim mesmo como tendo uma boa coordenação motora.

41 - Preciso praticar uma nova habilidade em vez de ler sobre ela ou ver um filme que a descreve.

\section{Inteligência Musical}

42 - Tenho uma voz agradável quando canto.

43 - Percebo quando uma nota musical está fora de tom.

44 - Frequentemente ouço música no rádio, em gravações, discos ou CDs.

45 - Toco um instrumento musical.

46 - Minha vida seria mais pobre se nela não houvesse música.

47 - Às vezes, eu me pego caminhando pela rua, com um jingle (vinheta) de televisão ou alguma música na cabeça.

48 - Posso marcar com facilidade o ritmo de uma música com um instrumento de percussão simples.

49 - Conheço as melodias de muitas canções e músicas diferentes.

50 - Se ouço uma seleção musical uma ou duas vezes, geralmente sou capaz de repeti-la com razoável precisão.

51 - Com frequência fico tamborilando ou cantando melodias enquanto estou trabalhando, estudando ou aprendendo alguma coisa nova.

\section{Inteligência Interpessoal}

52 - Sou o tipo de pessoa a quem os outros recorrem para pedir conselhos, no trabalho ou na vizinhança.

53 - Prefiro esportes coletivos como peteca, tênis, voleibol ou beisebol a esportes individuais como nadar ou correr.

54 - Quando tenho um problema, prefiro procurar uma pessoa para me ajudar, em vez de tentar resolvê-lo sozinho.

55 - Tenho pelo menos três amigos íntimos.

56 - Prefiro passatempos coletivos, como banco imobiliário ou canastra, a recreações individuais como videogames ou paciência.

57 - Gosto do desafio de ensinar uma outra pessoa, ou grupo de pessoas, ao desafio de fazer coisas que sei fazer.

58 - Eu me considero um líder (ou as pessoas assim me consideram).

59 - Sinto-me à vontade no meio de uma multidão. 
60 - Gosto de participar de atividades sociais relacionadas ao meu trabalho, igreja ou comunidade.

61 - Prefiro passar minhas noites em uma festa animada a ficar em casa sozinho.

\section{Inteligência Naturalista}

62 - Gosto de sair por aí com uma mochila nas costas, de acampar ou simplesmente de caminhar observando a natureza.

63 - Faço parte de uma organização de voluntários relacionada à natureza e quero ajudar a salvar o meio ambiente da destruição que ele está sofrendo.

64 - Gosto de ter animais de estimação.

65 - Tenho um passatempo relacionado à natureza (por exemplo: observar pássaros).

66 - Gosto de estudar temas relacionados à natureza (por exemplo: botânica, zoologia).

67 - Tenho facilidade em perceber as diferenças entre diferentes tipos de árvores, cães, pássaros ou outros tipos de fauna e flora.

68 - Gosto de ler revistas e livros, ou de assistir a programas de televisão ou filmes sobre a natureza.

69 - Prefiro passar as minhas férias em ambientes naturais como uma praia ou camping com trilhas ecológicas do que em locais urbanos ou culturais como um hotel dentro de uma cidade. 70 - Adoro visitar zoológicos, aquários e outros lugares onde podemos estudar o mundo natural.

71 - Tenho um jardim em minha casa e gosto muito de cuidar dele.

\section{Inteligência Intrapessoal}

72 - Costumo passar certo tempo sozinho meditando, refletindo ou pensando sobre questões importantes da vida.

73 - Já participei de sessões de orientação ou de seminários de crescimento pessoal para aprender mais sobre mim mesmo.

74 - Sou capaz de reagir às dificuldades com coragem.

75 - Tenho um passatempo ou interesse especial que guardo para mim mesmo.

76 - Tenho alguns objetivos importantes na minha vida sobre os quais reflito regularmente.

77 - Tenho uma visão realista das minhas forças e fraquezas (baseada em dados de outras fontes/pessoas).

78 - Prefiro passar um final de semana sozinho em uma cabana no mato, do que em um hotel chique cheio de gente.

79 - Eu me considero uma pessoa determinada, com ideias próprias.

80 - Mantenho um diário pessoal para registrar o que se passa na vida interior.

81 - Sou um profissional autônomo ou pelo menos tenho pensado muito em começar meu próprio negócio. 



\section{ANEXO 2}

Quadro com a divisão entre os cursos - com o total de enviados e total de respostas obtidas

\begin{tabular}{|c|c|c|c|}
\hline Unidade & Curso & Total Enviado & Total Respondido \\
\hline \multirow{3}{*}{$\mathrm{C} 3$} & Engenharia de Automação & 169 & 33 \\
\hline & Engenharia de Computação & 224 & 36 \\
\hline & Sistemas de Informação & 144 & 33 \\
\hline \multirow[t]{6}{*}{ ICEAC } & Administração & 432 & 39 \\
\hline & $\begin{array}{l}\text { Administração - Santo Antônio } \\
\text { da Patrulha }\end{array}$ & 87 & 9 \\
\hline & \begin{tabular}{|l|} 
Ciências Contábeis \\
\end{tabular} & 410 & 30 \\
\hline & Ciências Econômicas & 381 & 50 \\
\hline & Comércio Exterior & 100 & 8 \\
\hline & $\begin{array}{|lll|}\begin{array}{l}\text { Tecnologia em } \\
\text { Cooperativas }\end{array} & \text { Gestão de } \\
\end{array}$ & 39 & 8 \\
\hline \multirow[t]{12}{*}{$\mathrm{ICHI}$} & Arqueologia & 123 & 39 \\
\hline & Arquivologia & 155 & 27 \\
\hline & Biblioteconomia & 147 & 33 \\
\hline & Geografia Bacharelado & 118 & 16 \\
\hline & Geografia Licenciatura & 112 & 14 \\
\hline & História Bacharelado & 124 & 21 \\
\hline & História Licenciatura & 126 & 26 \\
\hline & Hotelaria & 89 & 12 \\
\hline & Psicologia & 185 & 47 \\
\hline & Tecnologia em Eventos & 78 & 9 \\
\hline & Turismo & 70 & 9 \\
\hline & TOTAL & 3.313 & 499 \\
\hline
\end{tabular}





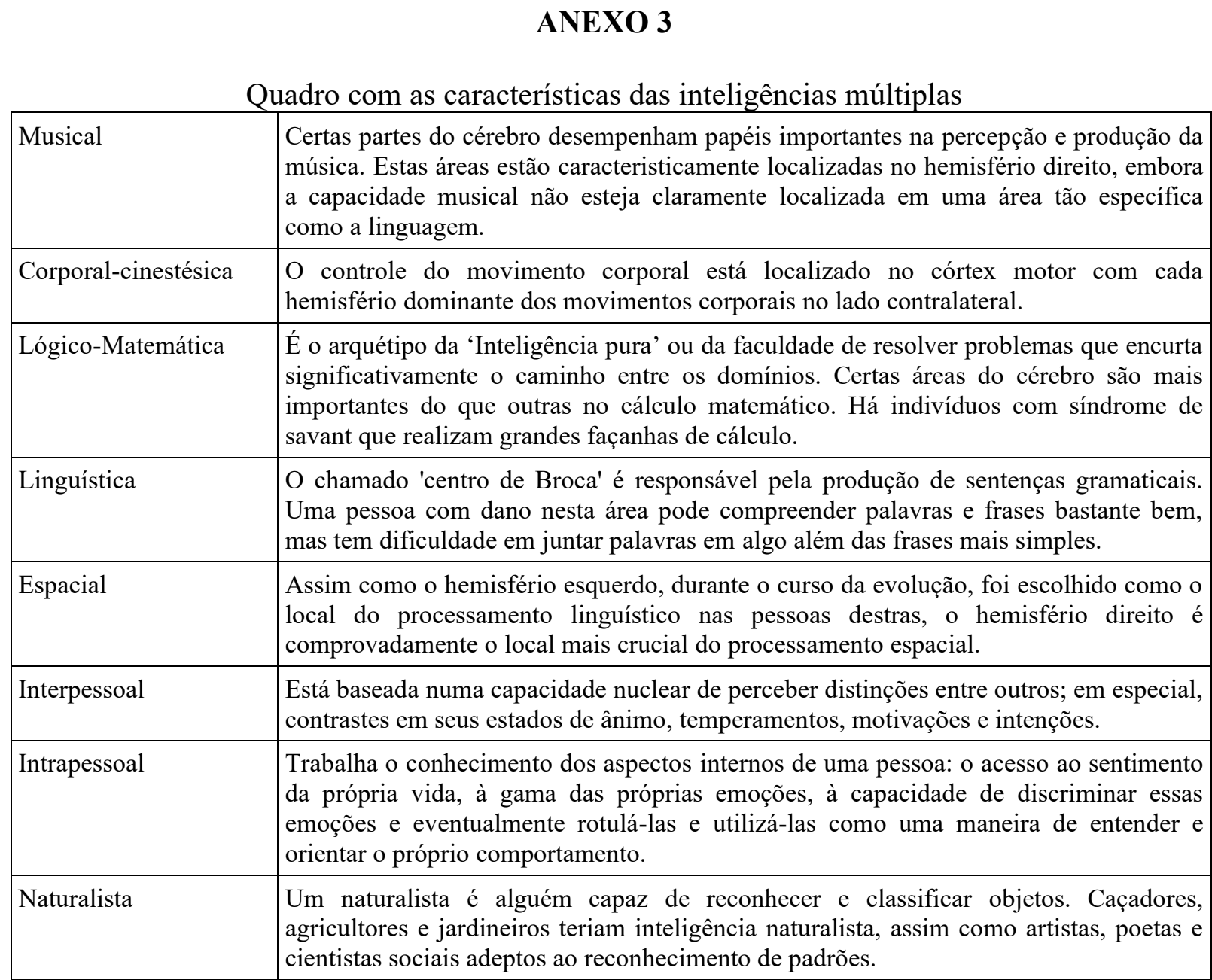

Fonte: Gardner (1995) e Visser, Ashton e Vernon (2006) 